\title{
AN ADAPTATION OF THE HEIDBRINK TRICHLORETHYLENE CIRCUIT FOR PAEDIATRIC ETHER ANAESTHESIA
}

\section{A J DUNN, M D ${ }^{1}$}

THIs MODIfication of the Heidbrink trichlorethylene circuit for ether anaesthesia was devised to meet the requests of some of our surgeons that endotracheal methods be made available for tonsillectomy patients of all ages

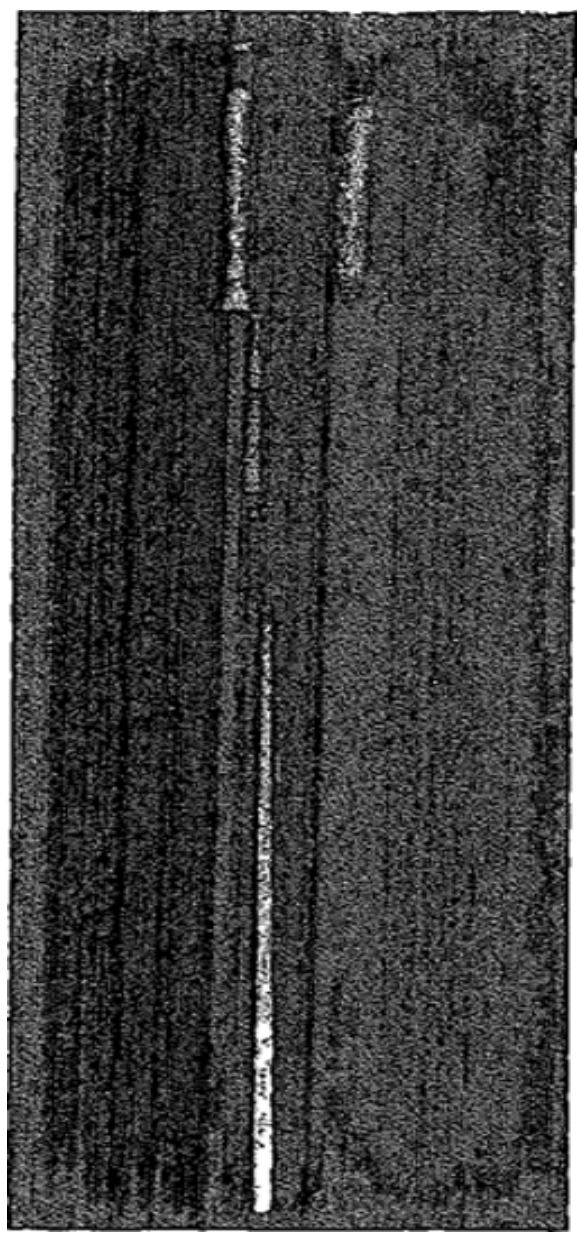

Figure 1

${ }^{1}$ Department of Anaesthesia, St Michael s Hospital, Toronto, Ont 345

Can Anaes Soc J, vol 7, no 3 July 1960 


\section{EqUIPMENT}

The only non standard apparatus needed is that show in in Figure 1 This pipe, used for bubbling oxygen and nitrous oxide through the Heidbrink ether bottle, was made from a discarded yoke fitting endotracheal connector to which was soldered a length of copper tubing of $3 / 8 \mathrm{in}$ internal diameter to reach to $1 / 2$ in from the bottom of the bottle (Fig 2) This pipe which fits the gas inlet

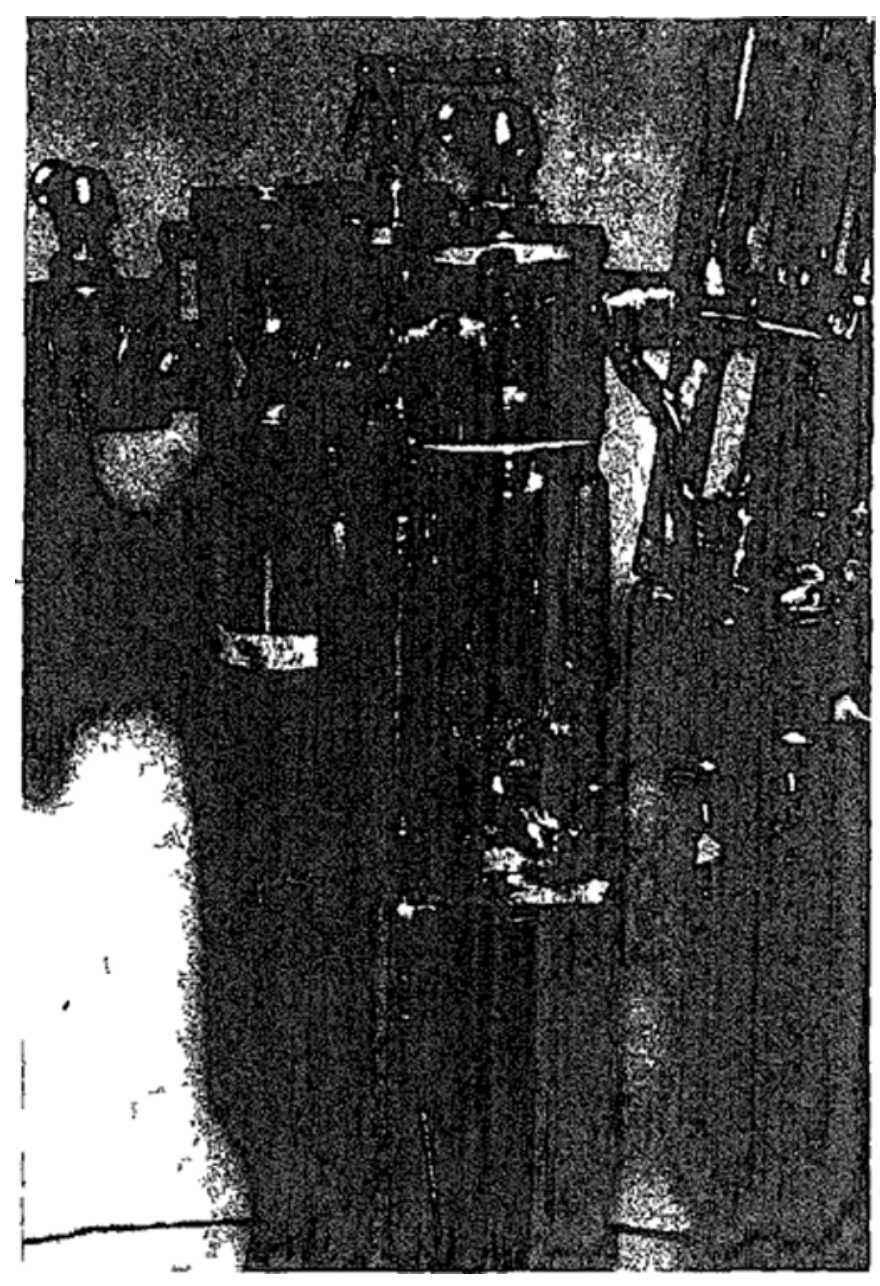

FIGURE 2

of the bottle is unsuitable for the closed circuit ether bottle where the pipe which accommodates it is the ether vapour outlet Gases and ether vapour are conducted to the patient through a length of rubber tubing which is confifected to a reservoir bag and non rebreathing valve with a catheter mount as shown in Figure 3 The endotracheal connector is held to the mouth gag by a blunted towel clip The headrest shown in Figure 4 combines lateral fixation with a scapular rest, which elıminates the need for manual hyperextension of the child $s$ 


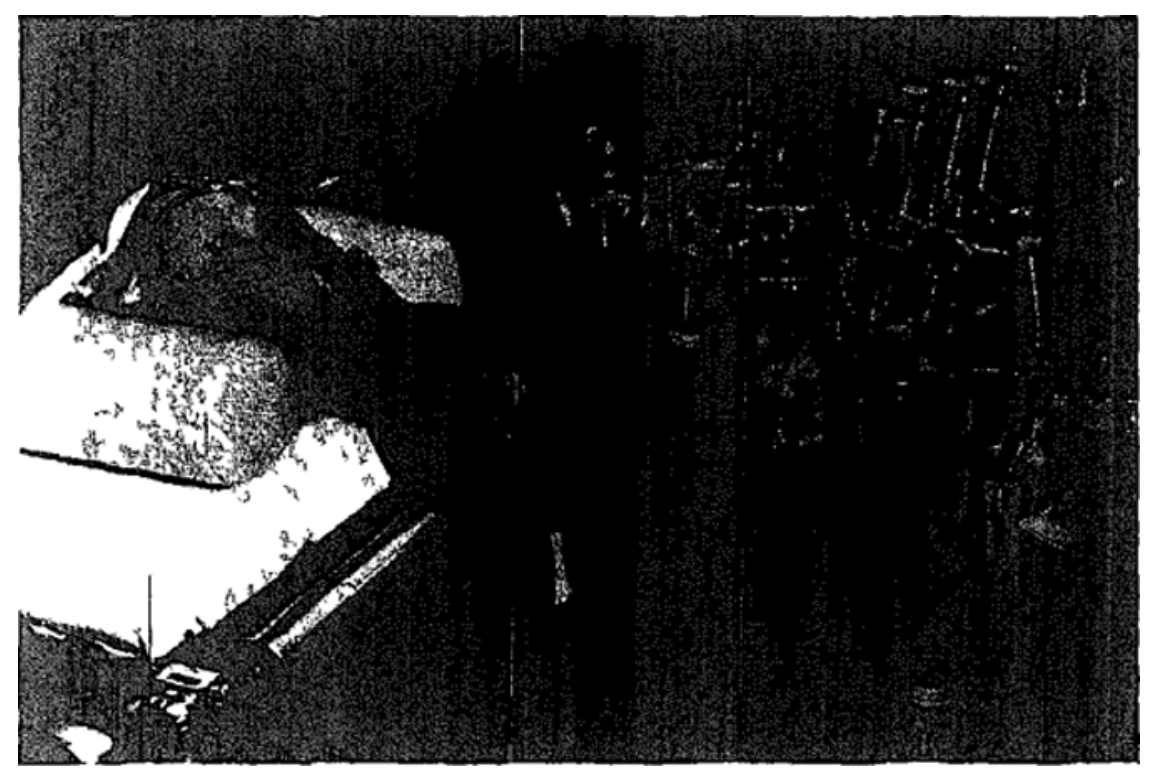

Figure 3

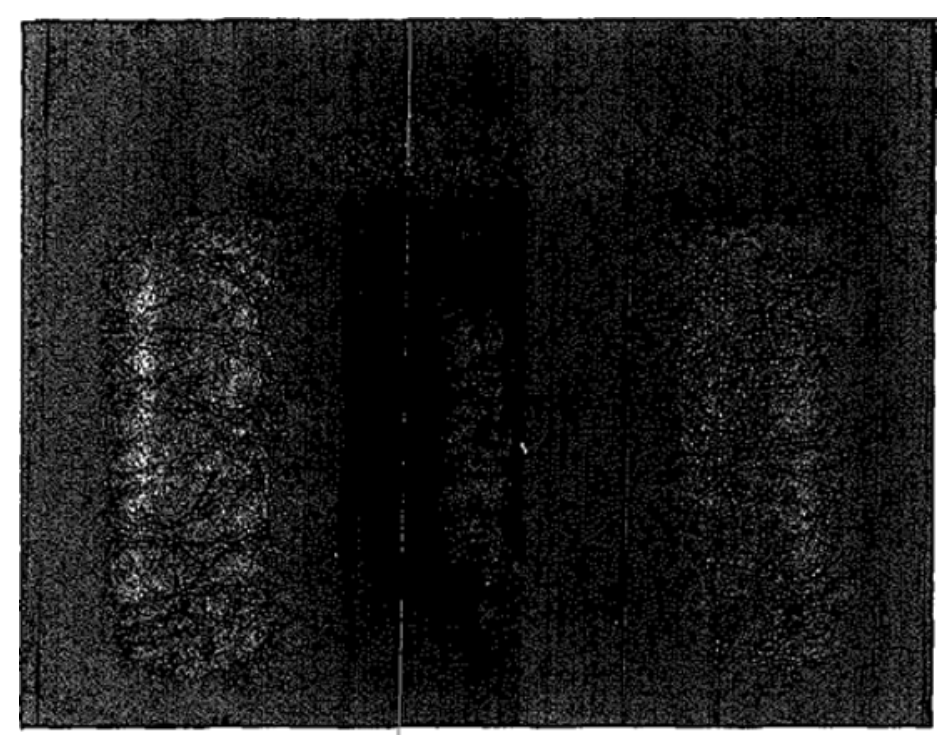

Figure 4 
neck, and keeps the pharynx dependent. An alternative arrangement for eye surgery is shown in Figure 5. Here the reservoir bag is kept at the bottle outlet, so that there is no interference with draping. In this picture may be seen the water-jacket, made from a suture jar, which maintains a more constant vapour concentration in longer eye procedures.

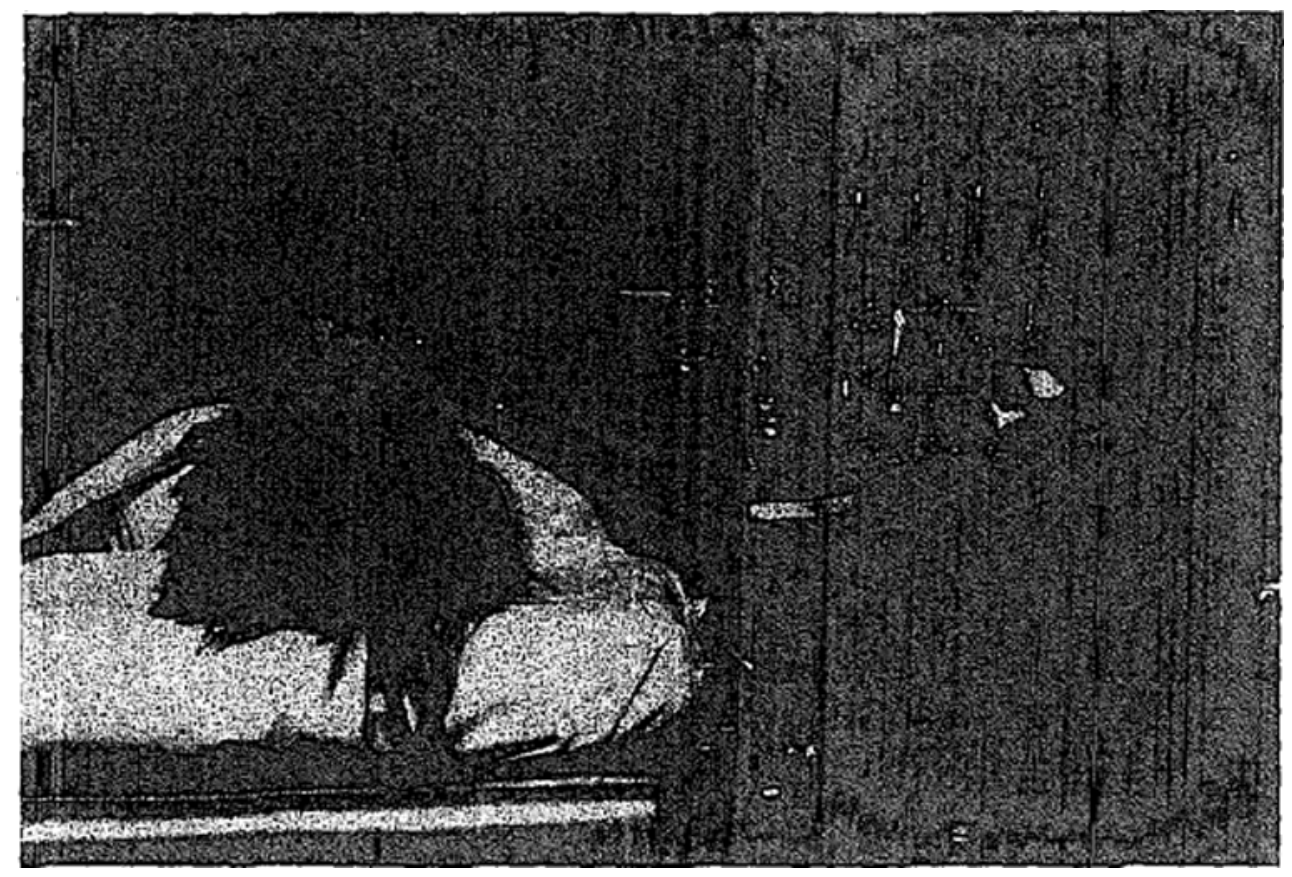

Figure 5

\section{TeChnique}

Anaesthesia is induced in atropinized, unsedated children by ethyl chloride and ether, and the child is intubated without relaxant, and connected to the reservoir bag. From this point on, anaesthetic depth is controlled by:

1. Varying the lever setting at a constant gas flow to cause more bubbling

2. Varying the total gas flow, at a constant lever setting, above minute volume needs

3. Varying the $\mathrm{N}_{2} \mathrm{O} / \mathrm{O}_{2}$ ratio

4. Use of the water-jacket.

This apparatus is capable of producing deep anaesthesia very quickly; so a minimal rate of bubbling should be aimed at, that will maintain a quiet operative field. In many cases, ether can be discontinued after one tonsil has been removed, and $\mathrm{N}_{2} \mathrm{O}$ and $\mathrm{O}_{2}$ will suffice for the rest of the operation. The water-jacket is usually unnecessary for tonsillectomy, unless the surgeon is against intubation. In this case, the reservoir bag and valve are replaced by an ether hook, and the water-jacket gives a higher vapour concentration, and prevents frosting of the 
bottle at higher rates of bubbling Dead space can be minimized for small children with endotracheal tubes, by shortening the catheter mount until the valve and connector are in contact

\section{ADVANTAGES}

As Percheson and Carroll have sald (1), endotracheal intubation is the stne qua non of good paediatric anaesthesia It is indispensable to the proper use of the non rebreathing. Ayre's, and relaxant methods This apparatus frees the hands of the anaesthetist to do the major part of the operation, which he 15 usually required to do It places the reservorr bag in the field of vision of the anaesthetist, so that pupillary and respiratory signs are always available It eliminates the semi obstructed aurway so common with open methods It allows an oxygen rich atmosphere to be inhaled, so that dark blood need never be seen in the operative field Anaesthesia can be conducted at a lighter level with an endotracheal tube in place, so that reflexes usually return before the child leaves the theatre The apparatus is removable, so that the machine may be used for non-explosive anaesthesia

\section{Disadvantages}

Laryngitis and tracheitis are possible, but have not been seen in the author's cases The tube causes slight restriction of the operative field, to which the surgeon soon adapts

\section{Summary and Conclusions}

A flexible, controllable method of endotracheal ether anaesthesia för children has been described, using a simple modification of the Heidbrink trichlorethylene circuit This has proven sale and satisfactory in over 200 cases, of $\frac{1}{2}$ to 2 hours duration, with no complications due to the method

\section{ACKNOWLEDGMENTS}

I wish to thank Dr $T$ Molony, who designed the head cushoon shown, and Mr A Snnalowshi, for the photography

\section{Resumé}

Nous avons décrit une technıque d'anesthésıe pédiatrıque à l'éther, technique flexıble, contrôlable, endotrachéale, en modıfiant smplement le circust à trichlorethylène Heıdbrunk Cette façon de procéder s'est avêrée de toute sécurité et satısfaisante au cours de $200 \mathrm{cas}$, l'une duree variant de $\frac{x}{2}$ heure à 2 heures, et nous n'avons observé aucune complication attribuable à cette méthode

\section{RI:FERENCE}

1 Prrcheson \& Carroll Difficulties in Paediatric Anaesthesia Canad Annesth Soc J 6 115 (April, 1958) 